\title{
A hybrid bacterial foraging and modified particle swarm optimization for model order reduction
}

\author{
Hadeel N. Abdullah \\ Department of Electrical Engineering, University of Technology, Iraq
}

\begin{tabular}{l}
\hline \hline Article Info \\
\hline Article history: \\
Received Jul 16 2018 \\
Revised Oct 17, 2018 \\
Accepted Nov 10, 2018 \\
\hline Keywords: \\
BF \\
BF-MPSO \\
ISE \\
Model order reduction \\
PSO
\end{tabular}

\begin{abstract}
This paper study the model reduction procedures used for the reduction of large-scale dynamic models into a smaller one through some sort of differential and algebraic equations. A confirmed relevance between these two models exists, and it shows same characteristics under study. These reduction procedures are generally utilized for mitigating computational complexity, facilitating system analysis, and thence reducing time and costs. This paper comes out with a study showing the impact of the consolidation between the Bacterial-Foraging (BF) and Modified particle swarm optimization (MPSO) for the reduced order model (ROM). The proposed hybrid algorithm (BF-MPSO) is comprehensively compared with the BF and MPSO algorithms; a comparison is also made with selected existing techniques.
\end{abstract}

Copyright () 2019 Institute of Advanced Engineering and Science. All rights reserved.

\section{Corresponding Author:}

Hadeel N. Abdullah,

Department of Electrical Engineering,

University of Technology,

Al-Sinaa Street, Baghdad, Iraq.

Email: 30002@uoechnology.edu.iq

\section{INTRODUCTION}

Scientists and engineers are often challenged with the analysis, design, and synthesis of real-life problems due to the regularly increasing size of system models showing up by the present technology and societal and environmental processes. In such studies, the initial step is the refinement of a mathematical model which can be an alternative to the real problem. Modelling and controlling of complex-dynamicsystems (CDS) is the farthest essential areas of study in many engineering fields and sciences [1]-[3]. In various cases and engineering applications, the dynamic system model under the study can be complicated to some extent and pose challenges when used. Where there is high and complex mathematical model show exactly the problem at hand, but it is not suitable for the numerical simulation. To overcoming this problem, model order reduction (MOR) approach is used, which aims to convert a system model from higher order to a lower order to facilitate the computational complexity of such problem and has lately been intensively sophisticated for use with piecemeal more CDS inclusive both optimization and control [4]-[5] .

Various popular MOR methods for linear and nonlinear large-scale dynamical systems, are available in the researches for MOR [6]-[8]. The need for new innovative and advanced approaches is justified. Theories of evolutional computation are proposed [9] and mathematically formulated as a new way to model and control of CDS [10]-[12].

All the above-mentioned methods didn't take into account the merge between the BF and PSO for the reduced order model. This paper comes out with a study showing the impact of the consolidation between the BF and PSO for the reduced order model. As well as, the results are counterweight with the original BF and with the proposed MPSO. 


\section{PROBLEM FORMULATION} function:

A straight time-invariant single-input single-output framework can be described by the following

$$
G_{n}(s)=\frac{N_{n}(s)}{D_{n}(s)}=\frac{a_{0}+a_{1} s+a_{2} s^{2}+\ldots+a_{n-1} s^{n-1}}{b_{0}+b_{1} s+b_{2} s^{2}+\ldots+b_{n} s^{n}}
$$

Where

$$
\left.\begin{array}{l}
a_{i}: 0 \leq i \leq n-1 \\
\mathrm{~b}_{i}: 0 \leq i \leq n
\end{array}\right\} \text { are known as scalar constants. }
$$

To get the $r^{\text {th }}(r<n) \operatorname{ROM}\left(G_{r}(s)\right)$ which is represented in the form:

$$
G_{r}(s)=\frac{N_{r}(s)}{D_{r}(s)}=\frac{e_{0}+e_{1} s+e_{2} s^{2}+\ldots+e_{r-1} s^{r-1}}{f_{0}+f_{1} s+f_{2} s^{2}+\ldots+b_{r} s^{r}}
$$

Where $e_{i}: 0 \leq i \leq r-1, f_{i}: 0 \leq i \leq r$. The integral-square-error (ISE) between $G_{r}(s)$ and $G_{n}(s)$ models is calculated to gauge the quality of the ROM. ISE is known by:

$$
I S E=\sum_{i=0}^{n}\left[y\left(t_{i}\right)-y_{r}\left(t_{i}\right)\right]^{2}
$$

Where $y\left(t_{i}\right)$ and $y_{r}\left(t_{i}\right)$ are the unit step responses of the original and ROM, correspondingly. The transfer function matrix of the multi_input multi_output system can be symbolized in the formula:

$$
G_{n}(s)=\frac{1}{D_{n}(s)}\left[\begin{array}{cccc}
a_{11}(s) & a_{12}(s) & \ldots & a_{1 p}(s) \\
a_{21}(s) & a_{22}(s) & \ldots & a_{2 p}(s) \\
\ldots & \ldots & \ldots & \ldots \\
a_{m 1}(s) & a_{m 2}(s) & \ldots & a_{m p}(s)
\end{array}\right]
$$

where $p=$ no. of input and $m=$ no. of output.

$$
g_{i j}(s)=\frac{a_{i j}(s)}{D_{n}(s)}
$$

where $i=1,2, \ldots, p, \quad j=1,2, \ldots, m$

To get $\left(r^{\text {th }}<n\right)$ ROM represented in the form of:

$$
G_{r}(s)=\frac{1}{D_{r}(s)}\left[\begin{array}{cccc}
e_{11}(s) & e_{12}(s) & \ldots & e_{1 p}(s) \\
e_{21}(s) & e_{22}(s) & \ldots & e_{2 p}(s) \\
\ldots & \ldots & \ldots & \ldots \\
e_{m 1}(s) & e_{m 2}(s) & \ldots & e_{m p}(s)
\end{array}\right]
$$

The overall form of $R_{i j}(s)$ from $G_{r}(s)$ is reserved as:

$$
R_{i j}(s)=\frac{e_{i j}(s)}{D_{r}(s)}
$$


To obtain the $r^{\text {th }}$ order reduced transfer matrix $G_{r}(s)$, the factors of the communal denominator $D_{r}(s)$ and the numerator $e_{i j}(s)$ of the $G_{r}(s)$ are designed by decreasing the ISE between the $g_{i j}(s)$ and $R_{i j}(s)$ order models.

\subsection{BF algorithm}

Recently, BF has become increasingly suitable as a global optimization technique in science and engineering subjects [13], [14]. The basic structural details of the BF algorithm are depicted in Figure 1.

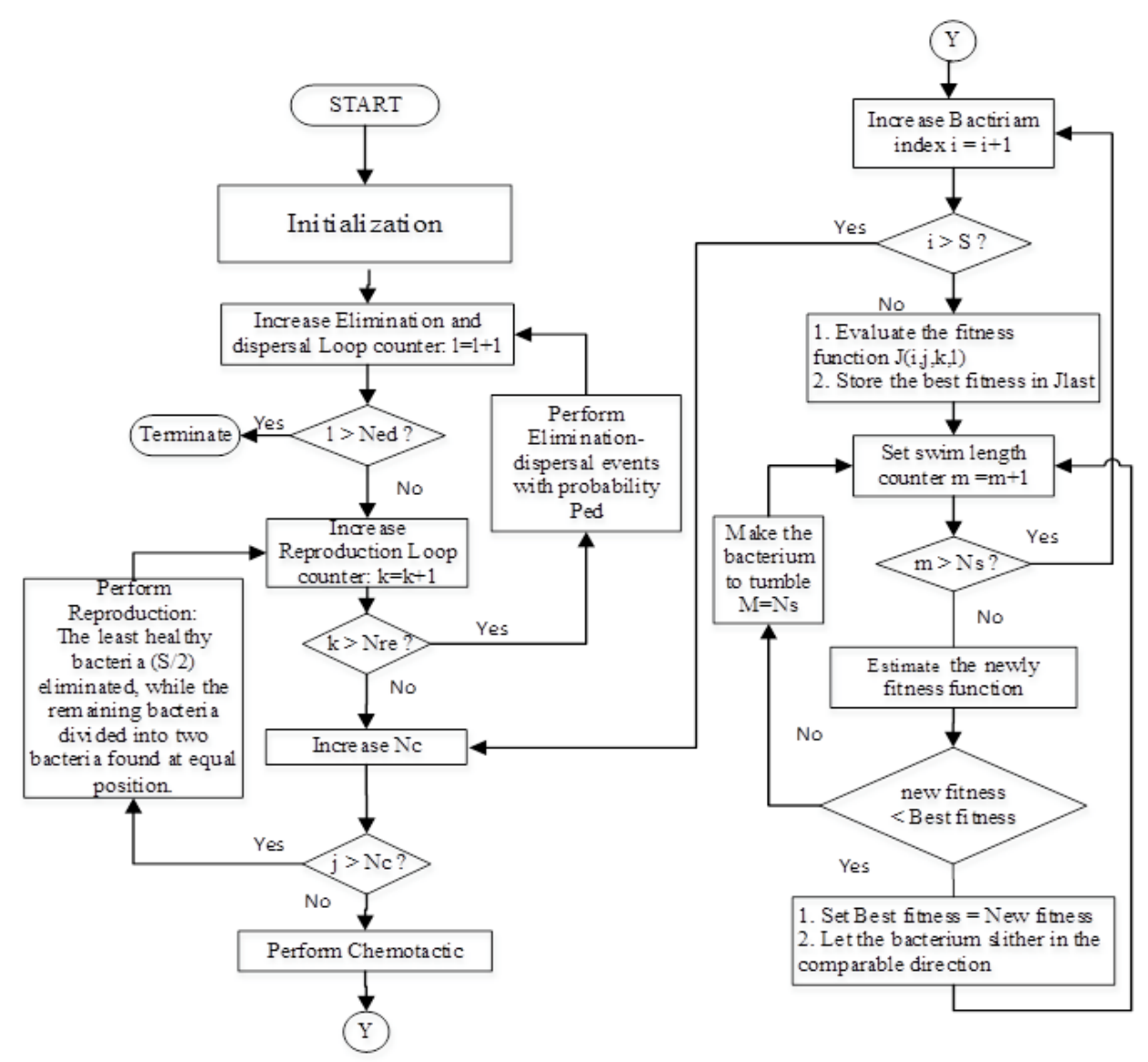

Figure 1. Basic structural of the BF algorithm

\subsection{MPSO algorithm}

PSO has seen many changes since it's introduced by Eberhart and Kennedy [15]. Whenever researchers learn about this technology, new versions are discovered, incorporated into new applications. PSO is a populace grounded streamlining tool in which the framework is set through various arbitrarypossibility elements famous as particles. Every particle takes a position $\left(X_{t}^{i}\right)$ and $\operatorname{speed}\left(\mathrm{V}_{t}^{i}\right)$, which are refreshed by the accompanying equations:

$$
\begin{aligned}
& v_{t+1}^{i}=w \cdot v_{t}^{i}+c_{1} r_{1}\left(P_{\text {Lbest }}^{i}-x_{t}^{i}\right)+c_{2} r_{2}\left(P_{G b e s t}^{i}-x_{t}^{i}\right) \\
& x_{t+1}^{i}=x_{t}^{i}+v_{t+1}^{i}
\end{aligned}
$$

Where $w=$ is the inertia_weight factor, 
$c_{1-c_{2}}=$ the cognitive_social acceleration factors, $r_{1}-r_{2}=$ randomlly $[0,1]$,

$$
\begin{aligned}
& \mathrm{P}_{\text {Lbest }}^{i}=\text { the best result achieved by } i \text { particle } \\
& \mathrm{P}_{\text {Gbest }}^{i}=\text { the best result achieved by all particle }
\end{aligned}
$$
as follows:

Different approaches are beneficial in texts for adjusting [16]-[19]. The proposed MPSO described Step 1: Identify the factors of PSO.

Step 2: Create an initial populace with M particles.

Step 3: estimate the fitness of each particle.

Step 4: Update according to one of the strategies proposed by us in [19].

Step 5: Update $X_{t}^{i}$ and $V_{t}^{i}$ for each particle by using Equations (8) and (9).

Step 6: Check the termination conditions.

\subsection{BF-MPSO algorithm}

To improve the performance; recent methods combine the PSO and BF algorithms together [20]-[22]. Here we propose a hybrid algorithm (combining the features of BF and the proposed MPSO (BF-MPSO) to acquire a ROM as shown in Figure 2.

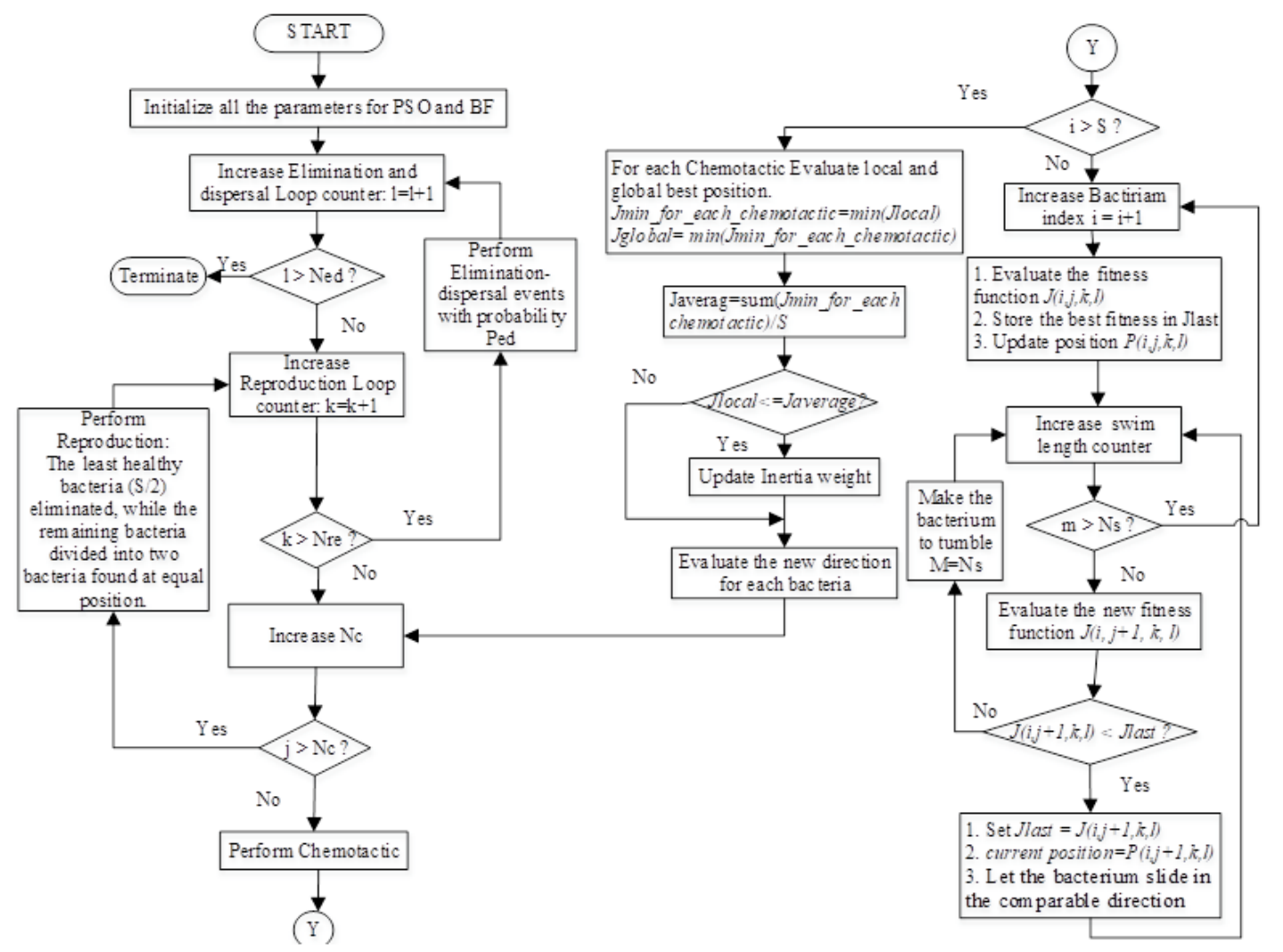

Figure 2. Basic structural of the proposed BF-MPSO algorithm

\section{RESULTS AND ANALYSIS}

In this segment, the proposed advancement strategies are attempting to limit the ISE as indicated in (3). The proposed techniques were actualized on a Pentium IV 3-GHz PC in the MATLAB 2010 condition. The exhibitions of the BF, MPSO, and BF-MPSO calculations were assessed utilizing consistent estimations of the underlying elements proclaimed in Table 1. 
Table 1. Factors Used for Modified PSO, BF and BF_MPSO Algorithms

\begin{tabular}{ll}
\hline \multicolumn{1}{c}{ Parameters } & \multicolumn{1}{c}{ Value } \\
\hline Swarm size & 50 \\
Maximum-number of generations & 50 \\
Cognitive-social acceleration factors $\left(c_{1}, c_{2}\right)$ & $1.2,0.8$ \\
Inertia-weight $\left(w_{\min }-w_{\max }\right)$ & $0.4-0.9$ \\
Number-of-bacteria $(S)$ & 20 \\
Chemotactic-steps $\left(N_{c}\right)$ & 200 \\
Maximum swim length $\left(N_{s}\right)$ & 2 \\
Dispersal-number-of-bacteria $(\mathrm{Ned})$ & 2 \\
Reproduction number $(\mathrm{Nre})$ & 2 \\
Dispersal probability $(\mathrm{Ped})$ & 0.05 \\
\hline
\end{tabular}

Example 1: Consider the 4th order system given in [4]:

$$
G_{4}(s)=\frac{14 s^{3}+249 s^{2}+900 s+1200}{s^{4}+19 s^{3}+102 s^{2}+190 s+120}
$$

The step-responses of the full and ROMs are displayed in Figure 3(a). Likewise, to assess the feature of the model in the frequency space Figure 3(b) shows the frequency-amplitude attributes of the full and ROMs. Keeping in mind the ISE and mean square error were computed, to compare the proposed method with different ROMs, as appeared in Table 2. A comparison for the conjunction of the fitness function with the number of generations for the two MPSO schemes is presented in Figure 4. Likewise, Figure 5 displays the variant of the minimum fitness with the number of chemotactic steps.

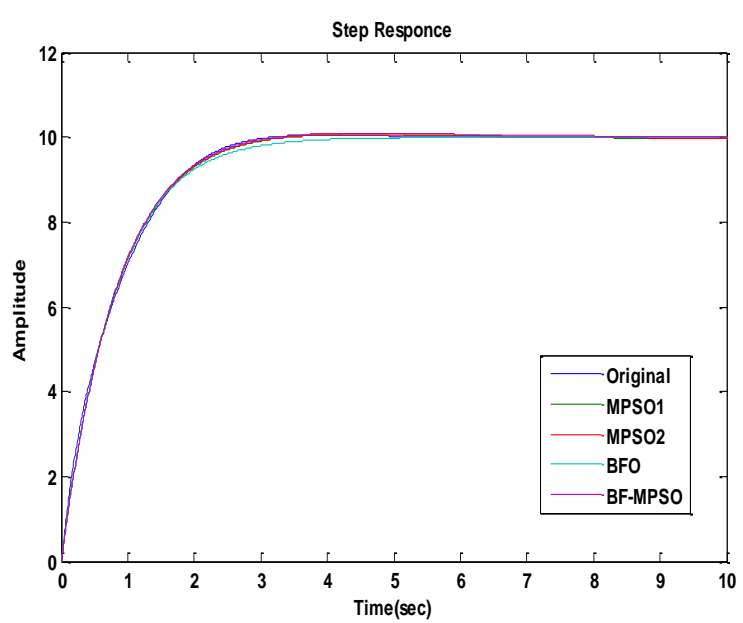

(a)

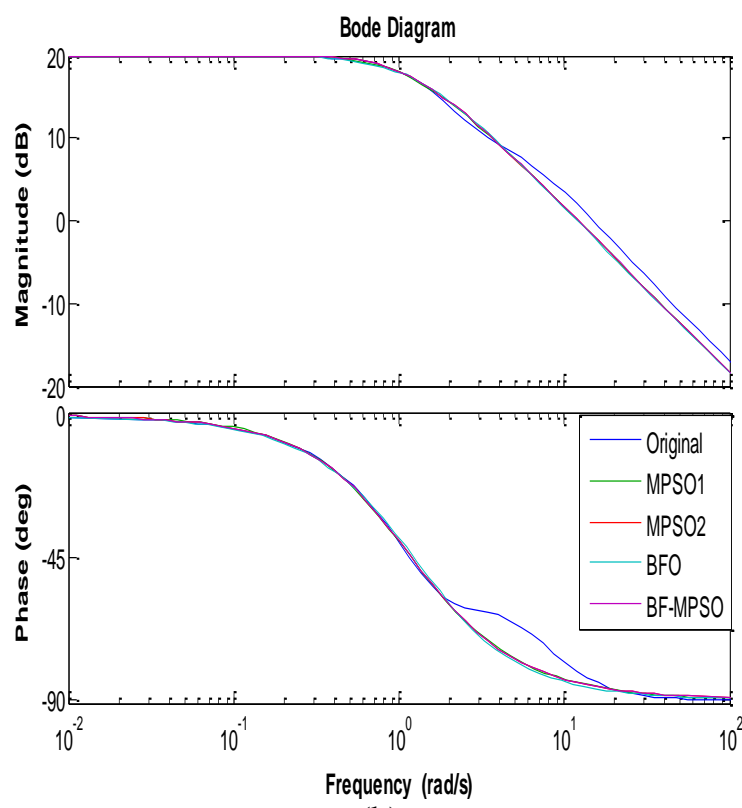

(b)

Figure 3. Original and reduced models responses for example 1 


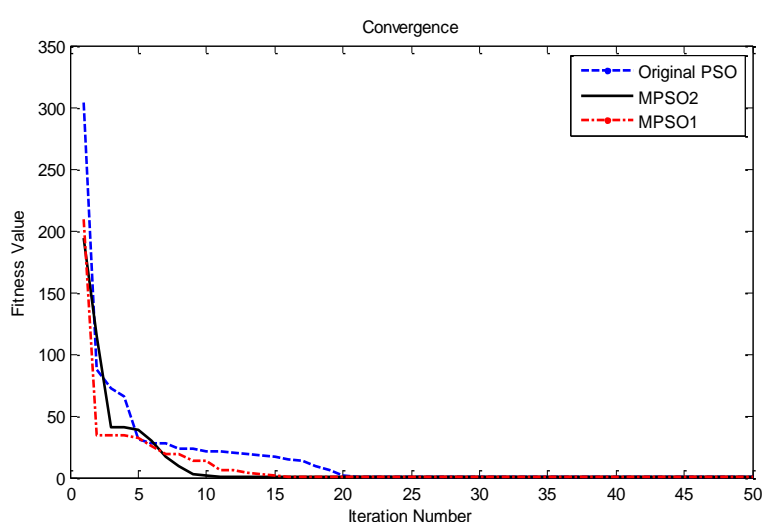

Figure 4. Evolution processes of the MPSO strategies for example 1

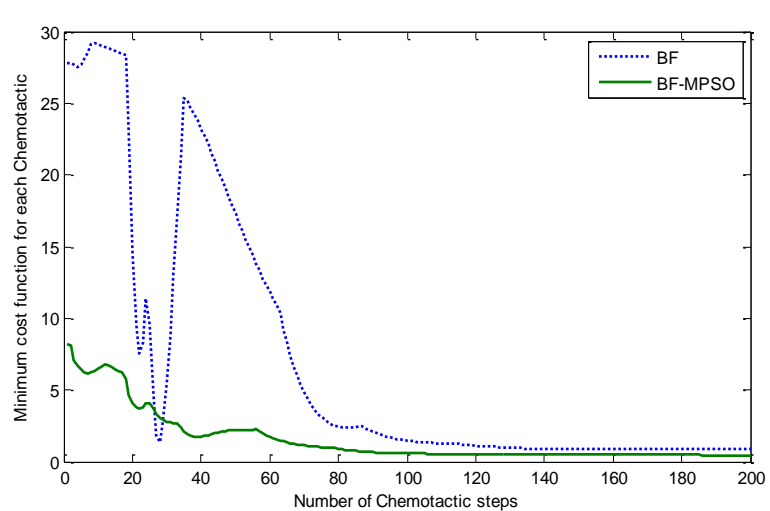

Figure 5. Evolution processes of BF and BF-MPSO methods for example 1

Example 2: Consider the $8^{\text {th }}$ system model presented in [5]:

$$
\frac{40320+185760 s+222088 s^{2}+122664 s^{3}+36380 s^{4}+5982 s^{5}+514 s^{6}+18 s^{7}}{40320+109584 s+118124 s^{2}+67284 s^{3}+22449 s^{4}+4536 s^{5}+546 s^{6}+36 s^{7}+s^{8}}
$$

The step responses of the full and ROMs are presented in Figure 6(a). Also, Figure 6(b) displays the frequency-amplitude attributes of the full and ROMs. Also, the ISE and mean square error were computed, to compare the proposed method with different ROMs, as appeared in Table 3. A comparison for the conjunction of the fitness function with the number of generations for the two MPSO schemes is presented in Figure 7. Figure 8 displays a plot of the variation of the minimum fitness with the number of chemotactic steps.

Table 2. Evaluation of Error Index Values for Example 1

\begin{tabular}{|c|c|c|c|}
\hline Method & ROM & $\begin{array}{l}\text { RMS- } \\
\text { Error }\end{array}$ & ISE \\
\hline \multirow{2}{*}{$\begin{array}{l}\text { Proposed } \\
\text { MPSO1 }\end{array}$} & $154.6 s+46.31$ & \multirow{2}{*}{0.0631} & \multirow{2}{*}{0.4020} \\
\hline & $\overline{12.82 s^{2}+18.74 s+4.66}$ & & \\
\hline \multirow{2}{*}{$\begin{array}{l}\text { Proposed } \\
\text { MPSO2 }\end{array}$} & $836.5 s+399.1$ & \multirow{2}{*}{0.0615} & \multirow{2}{*}{0.3820} \\
\hline & $\overline{69.39 s^{2}+112.9 s+40.03}$ & & \\
\hline \multirow{2}{*}{$\begin{array}{l}\text { Proposed } \\
\text { BF }\end{array}$} & $148.3 s+466.4$ & \multirow{2}{*}{0.0917} & \multirow{2}{*}{0.8504} \\
\hline & $\overline{12.5 s^{2}+51.73 s+46.64}$ & & \\
\hline \multirow{2}{*}{$\begin{array}{l}\text { Proposed } \\
\text { BFMPSO }\end{array}$} & $53.46 s+25.5$ & \multirow{2}{*}{0.0677} & \multirow{2}{*}{0.4638} \\
\hline & $4.421 s^{2}+7.196 s+2.55$ & & \\
\hline \multirow{2}{*}{ Ref. [4] } & $30 s+40$ & \multirow{2}{*}{0.1428} & \multirow{2}{*}{2.0609} \\
\hline & $3 s^{2}+6 s+4$ & & \\
\hline \multirow[b]{2}{*}{ Ref. [22] } & $12.0166 s+12.0226$ & \multirow[b]{2}{*}{0.0665} & \multirow[b]{2}{*}{0.4472} \\
\hline & $\overline{1.016 s^{2}+2.1155 s+1.202}$ & & \\
\hline \multirow{2}{*}{ Ref. [7] } & $2.8863 s+51.4892$ & \multirow{2}{*}{0.3146} & \multirow{2}{*}{9.9998} \\
\hline & $\overline{s^{2}+4.15032 s+5.1489}$ & & \\
\hline \multirow{2}{*}{ Ref. [8] } & $14 s+12.53$ & \multirow{2}{*}{0.3016} & \multirow{2}{*}{9.1872} \\
\hline & $\overline{s^{2}+2.138 s+1.253}$ & & \\
\hline \multirow{2}{*}{ Ref. [23] } & 70.588 & \multirow{2}{*}{0.3301} & \multirow{2}{*}{11.003} \\
\hline & $s^{2}+5.2941 s+7.0588$ & & \\
\hline
\end{tabular}

Table 3. Evaluation of Error Index Values for Example 2

\begin{tabular}{|c|c|c|c|}
\hline Method & ROM & $\begin{array}{l}\text { RMS } \\
\text { Error }\end{array}$ & ISE \\
\hline \multirow{2}{*}{$\begin{array}{l}\text { Proposed } \\
\text { MPSO1 }\end{array}$} & $340.4 s+104.3$ & \multirow[b]{2}{*}{0.0095} & \multirow[b]{2}{*}{0.0092} \\
\hline & $\overline{19.97 s^{2}+137.7 s+104.3}$ & & \\
\hline \multirow{2}{*}{$\begin{array}{l}\text { Proposed } \\
\text { MPSO2 }\end{array}$} & $682 s+208.8$ & \multirow[b]{2}{*}{0.0075} & \multirow[b]{2}{*}{0.0057} \\
\hline & $\overline{40.13 s^{2}+277.4 s+209.8}$ & & \\
\hline \multirow{2}{*}{$\begin{array}{l}\text { Proposed } \\
\text { BF }\end{array}$} & $40.89 s+14.96$ & \multirow{2}{*}{0.0569} & \multirow{2}{*}{0.3281} \\
\hline & $\overline{1.908 s^{2}+17.15 s+14.65}$ & & \\
\hline \multirow{2}{*}{$\begin{array}{l}\text { Proposed } \\
\text { BFMPSO }\end{array}$} & $90.75 s+28.23$ & \multirow{2}{*}{0.0086} & \multirow{2}{*}{0.0076} \\
\hline & $\overline{5.316 s^{2}+36.5 s+28.12}$ & & \\
\hline \multirow{2}{*}{ Ref. [4] } & $1.99 s+0.43184$ & \multirow{2}{*}{0.4371} & \multirow{2}{*}{19.296} \\
\hline & $\overline{s^{2}+1.17368 s+0.43184}$ & & \\
\hline \multirow{2}{*}{ Ref. [5] } & $6.7786 s+2$ & \multirow{2}{*}{0.1651} & \multirow{2}{*}{2.7825} \\
\hline & $\overline{s^{2}+3 s+2}$ & & \\
\hline \multirow[b]{2}{*}{ Ref. [22] } & $88.04 s+26.48$ & \multirow[b]{2}{*}{4.6467} & \multirow[b]{2}{*}{$\begin{array}{l}2.37 \times \\
10^{2}\end{array}$} \\
\hline & $\overline{4.021 s^{2}+28.59 s+2.648}$ & & \\
\hline
\end{tabular}




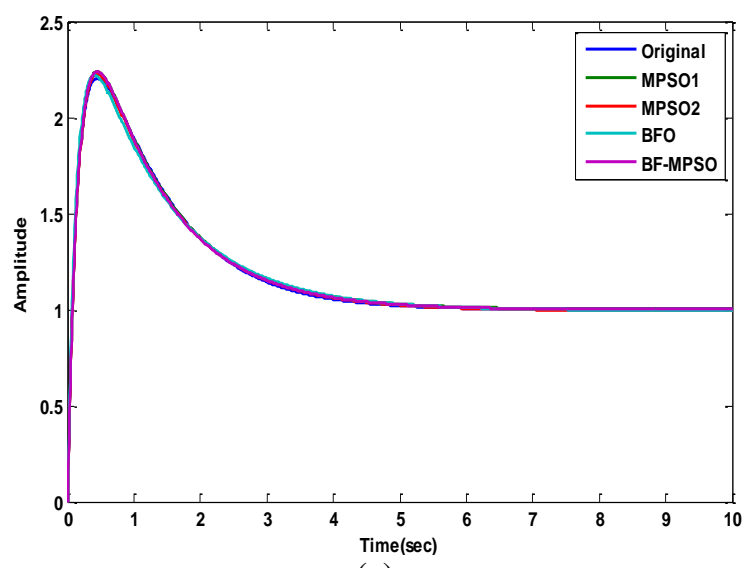

(a)

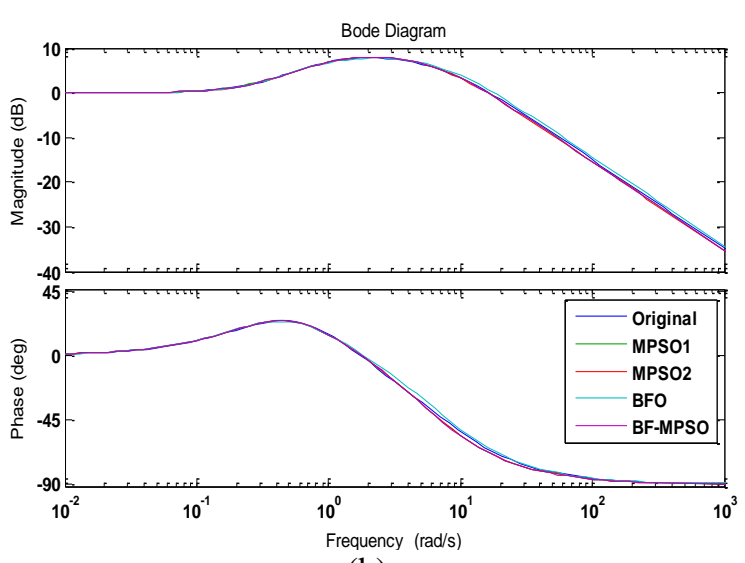

(b)

Figure 6. Original and reduced model responses for example 2: (a) step responses; (b) frequency responses

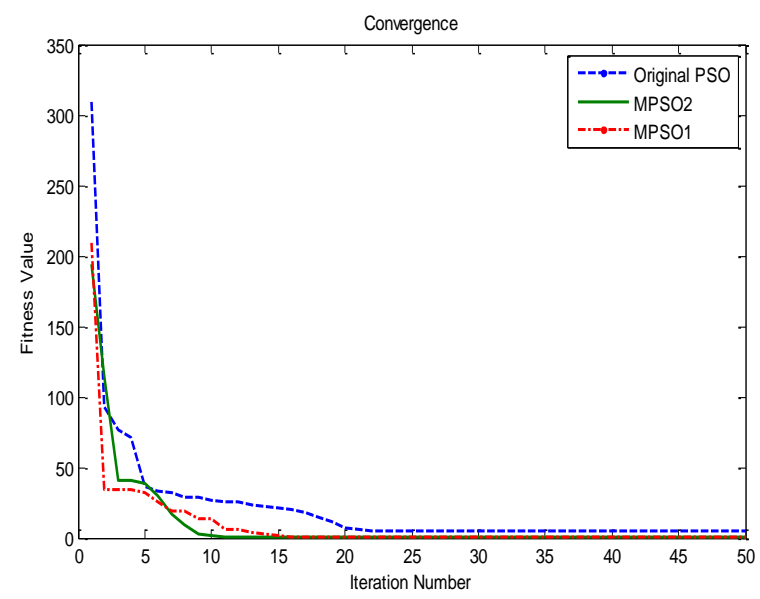

Figure 7. Evolution processes of two MPSO methods for Example 2

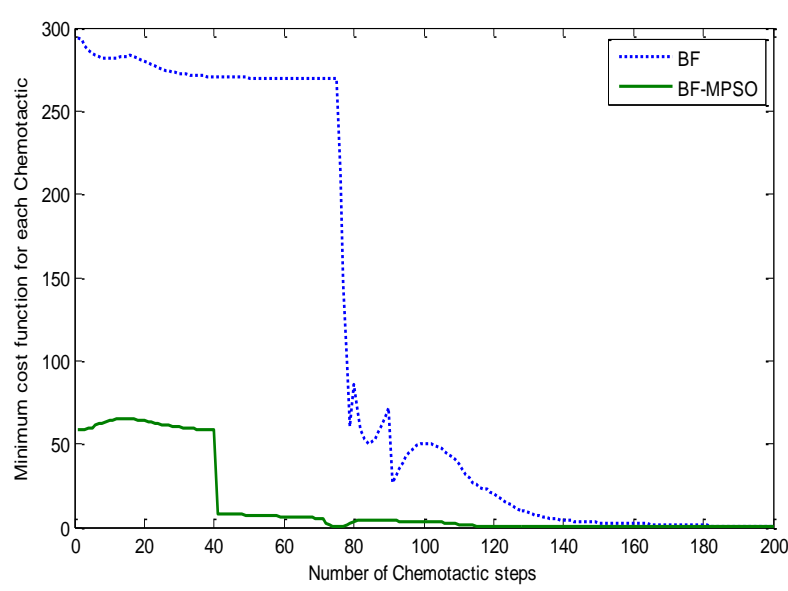

Figure 8. Evolution processes of BF and BF-MPSO methods for example 2

Example 3: A system model specified in [9], which is 6th order 2-input 2-output:

$$
G_{6}(s)=\left[\begin{array}{cc}
\frac{2(5+s)}{(1+\mathrm{s})(10+\mathrm{s})} & \frac{(4+\mathrm{s})}{(2+\mathrm{s})(5+\mathrm{s})} \\
\frac{(10+\mathrm{s})}{(1+\mathrm{s})(20+\mathrm{s})} & \frac{(6+\mathrm{s})}{(2+\mathrm{s})(3+\mathrm{s})}
\end{array}\right], G_{6}(s)=\frac{1}{D(s)}\left[\begin{array}{ll}
a_{11}(s) & a_{12}(s) \\
a_{21}(s) & a_{22}(\mathrm{~s})
\end{array}\right]
$$

Where:

$$
\begin{aligned}
& D(s)=(1+s)(2+s)(3+s)(5+s)(10+s)(20+s)=6000+13100 s+10060 s^{2}+3491 s^{3}+571 s^{4}+41 s^{5}+s^{6} \\
& a_{11}(s)=6000+7700 s+3610 s^{2}+762 s^{3}+70 s^{4}+2 s^{5} \\
& a_{12}(s)=2400+4160 s+2182 s^{2}+459 s^{3}+38 s^{4}+s^{5} \\
& a_{21}(s)=3000+3700 s+1650 s^{2}+331 s^{3}+30 s^{4}+s^{5} \\
& a_{22}(s)=6000+7700 s+3610 s^{2}+601 s^{3}+42 s^{4}+s^{5}
\end{aligned}
$$

By utilizing the second procedure of the MPSO calculation, the ROM system $G_{2}(s)$ was: 


$$
G_{2}(s)=\frac{\left[\begin{array}{cc}
(1.317 s+2.998) & (1.031 \mathrm{~s}+1.202) \\
(0.5782 s+1.499) & (1.781 \mathrm{~s}+3.014)
\end{array}\right]}{(s+3)(\mathrm{s}+1)}
$$

The step responses of the full and ROMs are displayed in Figure 9(a). Likewise, Figure 9(b) displays the frequency-amplitude features of the full and ROMs. To compare the proposed method with different ROMs, the ISE and mean square error were computed, as shown in Table 4.

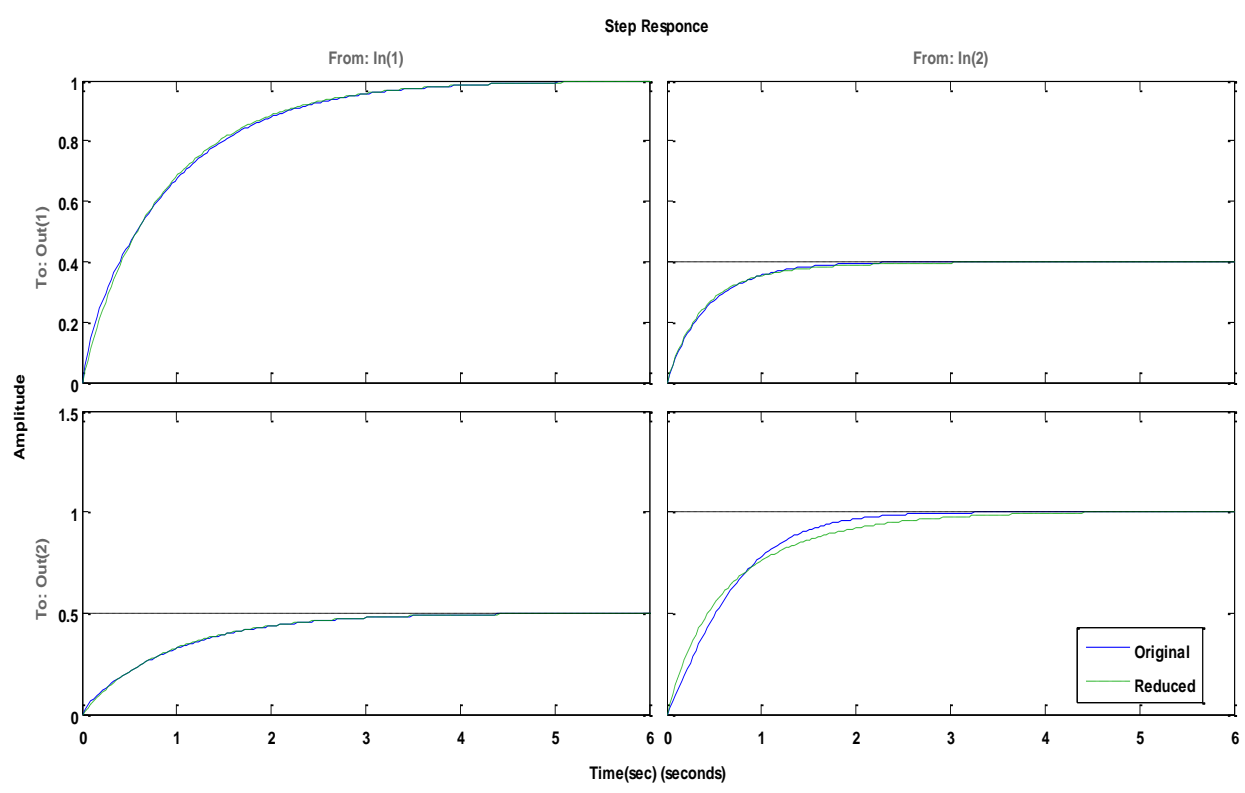

(a)

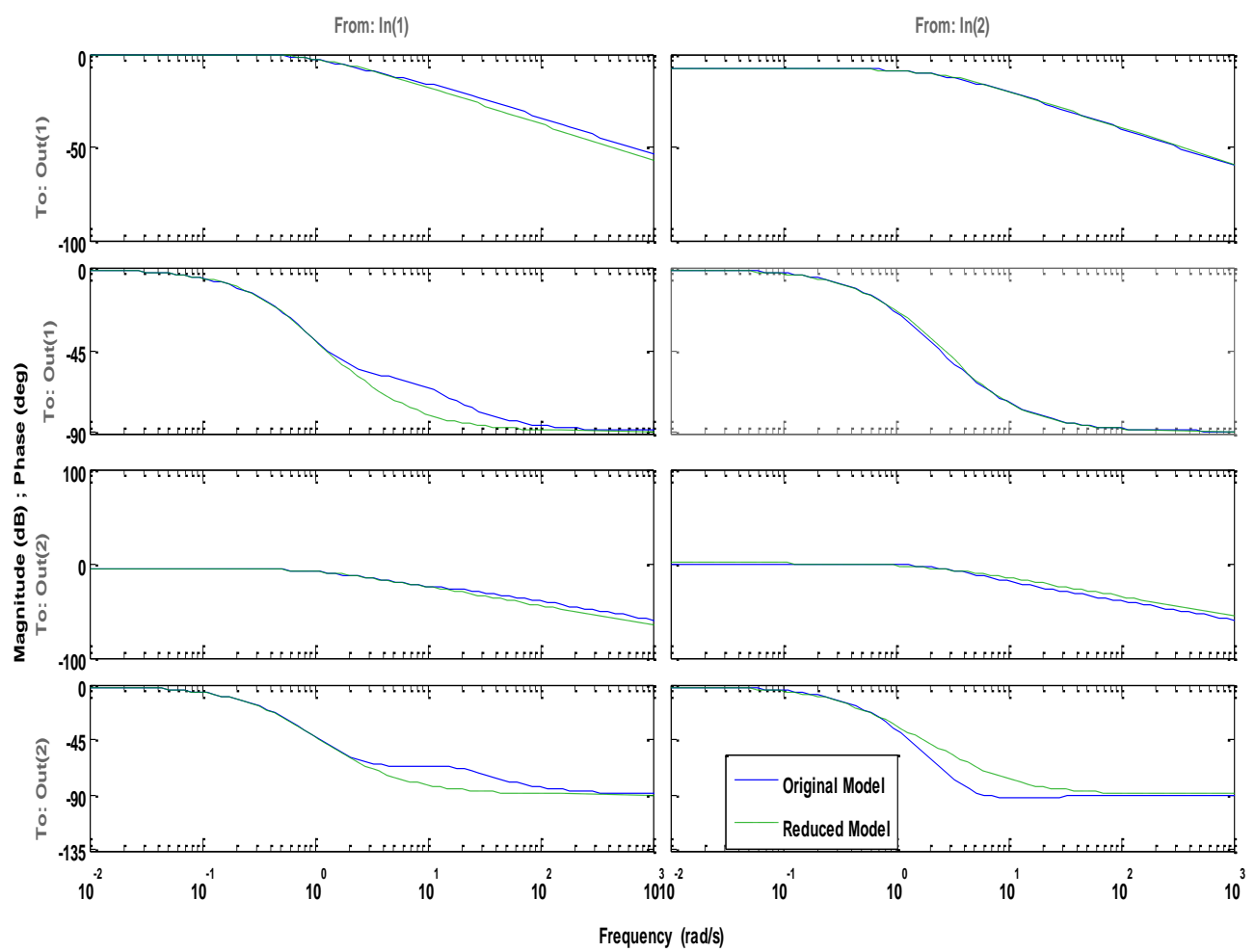

(b)

Figure 9. Original and reduced model responses for example 3 


\begin{tabular}{|c|c|c|c|c|c|}
\hline Method & Reduced Model & R11 & $\mathrm{R} 12$ & $\mathrm{R} 21$ & $\mathrm{R} 22$ \\
\hline $\begin{array}{l}\text { Proposed } \\
\text { MPSO2 }\end{array}$ & $\begin{array}{l}r_{11}=1.317 s+2.998 \\
r_{12}=1.031 s+1.202 \\
r_{21}=0.5782 s+1.499 \\
r_{22}=1.781 s+3.014 \\
D_{r}=\left(s^{2}+4 s+3\right)\end{array}$ & $\begin{array}{l}\text { RMS Error }= \\
0.004504 \\
\text { ISE = } \\
0.004077\end{array}$ & $\begin{array}{l}\text { RMS Error }= \\
0.001927 \\
\text { ISE }= \\
7.465 \times 10^{-4}\end{array}$ & $\begin{array}{l}\text { RMS Error }= \\
0.001475 \\
\text { ISE }= \\
4 . \times 10^{-4}\end{array}$ & $\begin{array}{l}\text { RMS Error }= \\
0.017657 \\
\text { ISE }= \\
0.062667\end{array}$ \\
\hline Ref. [9] & $\begin{array}{l}r_{11}=1.328 s+3.104 \\
r_{12}=1.034 s+1.241 \\
r_{21}=0.5818 s+1.552 \\
r_{22}=1.824 s+3.104 \\
D_{r}=\left(s^{2}+4.109 s+3.104\right)\end{array}$ & $\begin{array}{l}\text { RMS Error }= \\
0.004332 \\
\mathrm{ISE}= \\
0.003772\end{array}$ & $\begin{array}{l}\text { RMS Error }= \\
0.002527 \\
\mathrm{ISE}= \\
0.001283\end{array}$ & $\begin{array}{l}\text { RMS Error }= \\
0.001423 \\
\mathrm{ISE}= \\
4.068 \times 10^{-4}\end{array}$ & $\begin{array}{l}\text { RMS Error }= \\
0.018692 \\
\text { ISE }= \\
0.070228\end{array}$ \\
\hline Ref. [23] & $\begin{array}{l}r_{11}=-1.541 s+8.946 \\
r_{12}=0.9941 s+3.579 \\
r_{21}=-0.994 s+4.473 \\
r_{22}=0.5468 s+8.946 \\
D_{r}=\left(s^{2}+6.511 s+8.946\right)\end{array}$ & $\begin{array}{l}\text { RMS Error }= \\
0.047831 \\
\text { ISE }= \\
0.459849\end{array}$ & $\begin{array}{l}\text { RMS Error = } \\
6.634 \times 10^{-5} \\
\mathrm{ISE}= \\
8.845 \times 10^{-7}\end{array}$ & $\begin{array}{l}\text { RMS Error }= \\
0.025207 \\
\text { ISE }=0.127719\end{array}$ & $\begin{array}{l}\text { RMS Error = } \\
0.004436 \\
\text { ISE }= \\
0.003955\end{array}$ \\
\hline Ref. [24] & $\begin{array}{l}r_{11}=1.079 s+0.7091 \\
r_{12}=0.9031 s+0.2837 \\
r_{21}=0.1955 s+0.3546 \\
r_{22}=0.6895 s+80.7091 \\
D_{r}=\left(s^{2}+1.548 s+0.7091\right)\end{array}$ & $\begin{array}{l}\text { RMS Error = } \\
0.027311 \\
\text { ISE }= \\
0.149925\end{array}$ & $\begin{array}{l}\text { RMS Error }= \\
0.059892 \\
\text { ISE }= \\
0.720996\end{array}$ & $\begin{array}{l}\text { RMS Error }= \\
0.039632 \\
\text { ISE }= \\
0.315713\end{array}$ & $\begin{array}{l}\text { RMS Error = } \\
0.069859 \\
\text { ISE }= \\
0.980948\end{array}$ \\
\hline
\end{tabular}

\section{CONCLUSION}

In this paper, we presented a comparative study of three algorithms for ROM optimization problems, namely: MPSO, BFO, and MPSO_BF. From Figures 3, 6, and 9, unmistakably observed that the suggested techniques keep up steady state value and stability in the ROMs, while Figures 4 and 7 delineate that the convergence speed of the second MPSO strategy is the fastest among the two strategies. Figures 5 and 8 illustrate that the speed of convergence and additionally the precision of the proposed BF-MPSO is better than that of BF. In addition, these algorithms can use a smaller number of chemotactic steps, which makes them faster. At long last, the information showed in Tables 2, 3, and 4 exhibits that the proposed calculation performs well in contrast with other accessible procedures.

\section{REFERENCES}

[1] Leitch, R.R., "Modelling of Complex Dynamic Systems," In IEEE Proceedings D (Control Theory and Applications) (Vol. 134, No. 4, pp. 245-250). IET Digital Library, July 1987.

[2] Feldmann, P. and Freund, R.W., "Efficient Linear Circuit Analysis by Padé Approximation Via the Lanczos Process," IEEE Transactions on Computer-Aided Design of Integrated Circuits and Systems, 14(5): 639-649, 1995.

[3] Yavarian, K., Hashemi, F. and Mohammadian, A., "Design of Intelligent PID Controller for AVR System Using an Adaptive Neuro Fuzzy Inference System," International Journal of Electrical and Computer Engineering (IJECE), 4(5), pp.703-718, 2014.

[4] Friedland, B. and Hutton, M. F., "Routh Approximations for Reducing the Order of the Linear Time-Invariant System," IEEE Transaction on Automatic Control, 20(3): 329-337, 1975.

[5] Shamash, Y., "Linear System Reduction Using Pade Approximation to Allow Reduction of Dominant Model," International Journal of Control, 21(2): 257-272, 1975.

[6] Enns, D.F., "Model Reduction With Balanced Realizations: An Error Bound and a Frequency Weighted Generalization," In Decision and Control, 1984. The 23rd IEEE Conference on (Vol. 23, pp. 127-132). IEEE, 1984, December.

[7] Vishwakarma, C.B., and Prasad, R., "A Clustering Method for Reducing the Order of Linear System Using Pade Approximation," IETE journal of research, 54(5): 326-330, 2008.

[8] Mukherjee, S. and Mittal, R.C., "Order Reduction Using the Mixed Method," In IECON 2012-38th Annual Conference on IEEE Industrial Electronics Society (pp. 2384-2388). IEEE, October 2012.

[9] Vasu, G., Santosh, K.V.S. and Sandeep, G., March. "Reduction of Large-Scale Linear Dynamic SISO and MIMO Systems Using Differential Evolution Optimization Algorithm," In Electrical, Electronics and Computer Science (SCEECS), 2012 IEEE Students' Conference on (pp. 1-6). IEEE, 2012. 
[10] Parmar, G., Mukherjee, S. and Rasad, R., "Reduced Order Modelling of Linear Mimo Systems Using Genetic Algorithm," International Journal of Simulation Modelling (IJSIMM), 6(3): 173-184, 2007.

[11] Peng, C. and Wang, Y., "A Hybrid Simplex-Harmony Search Algorithm and its Application to the Model Reduction of Linear Systems," In Control Conference (CCC), 2010 29th Chinese, pp. 5272-5275. IEEE, July 2010.

[12] Abdullah, H.N., Sun, H.S. and Abd, M.K., "Design LQG/LTR Controller for Higher Order Systems Based on the Reduction Model," Power and Energy Engineering Conference (APPEEC), 2016 IEEE PES Asia-Pacific, pp: 2276-2281, October 2016.

[13] Passino, K.M., "Bio Mimicry of Bacterial Foraging for Distributed Optimization and Control," IEEE Control Systems, 22(3): 52-67, 2002.

[14] Mishra, S., "A Hybrid Least Square-Fuzzy Bacterial Foraging Strategy for Harmonic Estimation," IEEE Transactions on Evolutionary Computation, 9(1): 61-73, 2005.

[15] Eberhart, R.C., and Kennedy, J., "Particle Swarm Optimization," Proceeding of IEEE International Conference on Neural Network. Perth, Australia, pp.1942-1948, 1995.

[16] Chatterjee, A. and Siarry, P., "Nonlinear Inertia Weight Variation for Dynamic Adaptation in Particle Swarm Optimization," Computers \& operations research, 33(3): 859-871, 2006.

[17] Zhang, L., Tang, Y., Hua, C., and Guan, X., "A New Particle Swarm Optimization Algorithm with Adaptive Inertia Weight based on Bayesian Techniques," Applied Soft Computing, 28: 138-149, 2015.

[18] Taherkhani, M. and Safabakhsh, R., "A Novel Stability-Based Adaptive Inertia Weight for Particle Swarm Optimization," Applied Soft Computing, 38: 281-295, 2016.

[19] Abdullah, H.N., "Reduction of Large-Scale Linear Dynamic SISO and MIMO Systems Using Modified Particle Swarm Optimization Algorithm," In Industrial Electronics and Applications (ICIEA), 2016 IEEE 11th Conference on (pp. 166-171). IEEE, June 2016.

[20] Korani, W.M., Dorrah, H.T. and Emara, H.M., "Bacterial Foraging Oriented by Particle Swarm Optimization Strategy for PID Tuning," In Computational Intelligence in Robotics and Automation (CIRA), 2009 IEEE International Symposium on (pp. 445-450). IEEE, December 2009.

[21] Hooshmand, R.A., and Soltani, S., "Fuzzy Optimal Phase Balancing of Radial and Meshed Distribution Networks Using BF-PSO Algorithm," IEEE Transactions on Power Systems, 27(1): 47-57, 2012.

[22] Panda, S., Tomar, S.K., Prasad, R. and Ardil, C., "Reduction of Linear Time-Invariant Systems Using RouthApproximation and PSO," International Journal of Applied Mathematics and Computer Sciences, 5(2): 82-89, 2009.

[23] Vishwakarma, C.B., and Prasad, R., "Order Reduction Using the Advantages of Differentiation Method and Factor Division Algorithm," Indian Journal of Engineering and Materials Sciences, vol. 15: 447-451, 2008.

[24] Prasad, R., "Pade Type Model Order Reduction for Multivariable Systems Using Routh Approximation," Computers \& Electrical Engineering, 26(6): 445-459, 2000. 